\title{
Application of 3D Effect in Furniture E-commerce Zexian $\mathrm{Nie}^{1}$, Dan $\mathrm{Xu}^{2}$, Wenquan Zhou ${ }^{3}$ and Ying $\mathrm{Yu}^{*}$ ${ }^{1}$ City College of Wuhan University of Science and Technology, Wuhan 430083, China ${ }^{2}$ City College of Wuhan University of Science and Technology, Wuhan 430083, China ${ }^{3}$ City College of Wuhan University of Science and Technology, Wuhan 430083, China * The Corresponding AuthorCorresponding author Ying Yu
}

Keywords: Furniture Design; 3D Effect; Electronic Commerce

\begin{abstract}
Through the analysis of the characteristics of the 3D effect in furniture design, this paper puts forward the integration of the 3D effect into the electronic commerce, and probes into how the $3 \mathrm{D}$ effect of the furniture design is applied in the electronic commerce and brings convenience.
\end{abstract}

\section{Preface}

Furniture refers to a class of appliances, which is essential for the rest, work and storage of human beings. From the practical point of view, it is a material product which is closely related to our life; from the aesthetic point of view, it is a functional art. Consumers buy furnitures in sales field with measurement in traditional, which makes a great drain on time, manpower, material resources and financial resources. With the change of people's consumption patterns on the Internet, this kind of bulky goods will inevitably be affected by the e-commerce model. Electronic commerce, also known as Online retailers, breaks the traditional mode of business operation, which is an innovative way to realize the global economy by means of network technology. The exhibition of massive furniture products on the Internet is tridimensional, which provides consumers with 360-degree observation of product appearance, as well as an intuitive access to various types of commodity attribute information, like be personally on the scene. A set of statistical data about the "Pearl River Delta regional furniture electricity supplier" shows that more than $80 \%$ of the furniture enterprises pay close attention to the electronic commerce, more than $60 \%$ furniture manufacturing enterprises is planning to implement, has been deeply involved in about 30\% and 5\%, has achieved good economic benefits. This means that more and more furniture manufacturers are getting rid of the traditional furniture distribution model, choosing innovative marketing model to grasp the dominance of the industrial chain. Then as a furniture designer should accurately grasp the needs of the market, pay attention to the 3D effect in furniture design and its role in e-commerce.

\section{Characteristics of 3D Effect of Furniture}

The 3D effect of furniture refers to the use of computer-aided software to create three-dimensional simulation images, the 3D effect brings new ideas and methods to furniture design, which becomes a new trend in design and creation. The "3DMAX" software is mainly used in furniture design, of which the production process can be divided into four stages: modeling, texturing, lighting and rendering.

(1) modeling is the process of making 2D design drawings into three-dimensional effects, which can be divided into two types: scene modeling and furniture modeling. Scene modeling refers to the construction of indoor space and supporting home, furniture modeling is the process of modeling the furniture through the actual size of furniture. Benefit from the variability of 3D software, we can make Chinese style, European style, simple style and other styles of furniture.

(2) texture refers to the creation of a more realistic model of furniture decoration material effect. Such as visual cortex, solid wood, sheet metal, organic glass, and so on, as well as tactile three-dimensional concave convex, matte effect.

(3) By comprehensive application of various types of lights in the 3DMAX software, the real 
effects of furniture models under the condition of different types, intensities, projection ranges of lights can be created, as well as a display of virtual scene of furniture, so it has been widely used.

(4) rendering, also called coloring, is the last link in the use of 3D software for the design of furniture, displaying lighting effects, shadow effects and surface texture effects by rendering. Beautiful 3D effect drawing is close to the photo, it can express the overall effect of furniture design in the early stages, which can provide consumers with a certain cognition.

The shape of the model determines the shape of the furniture, the texture shows the surface character of the furniture, lighting and rendering bring out the atmosphe of spatial effects of the whole furniture. The importance of 3D effect not only lies in the true picture, but also animation synthesis, scene simulation and multi angle dynamic scenes.

\section{The 3D Effects Bring Many Conveniences to Furniture E-commerce}

Initial Results. The 3D effect of furniture design is a means for designers to simulate the finished products by computer aided software in the early stage of design. Any product must adapt to the needs of the market and consumers with out foundation, as well as furniture design. The 3D effects of furniture design help designers to carry out the design work quickly and effectively, consumers can also see the full picture before the finished product. At the same time, businesses can collect consumers' feedback on furniture design in this way, so as to reduce the loss of furniture after trial-producing. Because of the authenticity and accuracy, as well as perfection of the texture and lighting, the businesses can offer on-demand customization by hunger marketing, which can cost saving, avoid waste and low price promotions. Hunger marketing mainly shows not mass-produced goods by different media, makes limited and timed marketing, Through the grasp of consumer goods in order to dilute the psychology of their full attention to the commodity and attention, stimulate the desire to buy, so as to sell a large number of goods in a short time.

Virtual Store. Due to the drawbacks of traditional furniture distribution model, many enterprises gradually began to get rid of traditional furniture stores, for multi-channel product sales. Under the impetus of the Internet economy, virtual store sales model gradually appears. As everyone knows that the virtual furniture store is a non-entity stores, the simplest e-commerce mode, it will direct the traditional store online, and offer the 360-dimensional interactive display of furniture stores through the 3D virtual technology, so that consumers can get Omni bearing observation at home, pick up the whole attribute information of goods intuitively, choose your favorite furniture. Virtual stores have many advantages. First, lower price than the real furniture store due to free rental space; secondly, more choices because of complete varieties; last, the numerous network platform, free-time shopping, online transactions convenient payment, online customer service to answer, door-to-door, responsible for the installation, convenient, save worry.

Exclusive Customization. The effect of 3D furniture breakthrough time and space constraints, its authenticity and flexibility are obvious to all, so the designer can help consumers to "tailor" by this means, offer more humane and personalized exclusive custom of fashion furniture. Exclusive customization can start from two aspects: first, designers can use computer software to restore the user's room, even apartment layout effect, make the real scene of $1: 1$, then watch the overall effect by putting designed furniture pictures into the apartment layout chart with 3D effects. In this way, it is very convenient to change material texture, colour and position of furniture, truly gained unique properties; second, understand the consumer's personalized requirements for furniture online and offline, including the size and working environment, timely display the modification of furniture design by $3 \mathrm{D}$ effects, and then put into production after confirmed by consumers, this interactive design of the consumer into a designer fully reflects the characteristics of furniture customization.

\section{Future Development Trend}

As a result of hot property market, China's furniture industry is bound to show an upward trend, China's economic development, the improvement of people's living and the expansion of export markets will effectively promote the further development of China's furniture industry. The 
structural optimization of furniture industry and product will further accelerate, the furniture product are developping in the direction of High-tech content, high quality, multi variety and multi function. The diversified development of 3D will bring new vitality and vigor to the furniture e-commerce.

3D Printing Technology to Promote Consumer Personality Design. As furniture e-commerce is an open market, the status of designers and consumers has undergone unprecedented changes, consumers can participate in the design by 3D effect and 3D printing sample of the furniture. Furniture 3D printing is a kind of technology based on the digital model document, using adhesive materials such as powdered metal or plastic, constructing the object by printing layer-by-layer.With out any machine work or any mold, you can directly build furniture models and parts from the computer graphics data, thus greatly shorten the product development cycle, improve productivity and reduce production costs. As the 3D effect of the furniture is a virtual three-dimensional effect in the two-dimensional space, to impact the consumer's visual senses, so the 3D printing finished product is a reduction of furniture in three-dimensional, to give consumers a real feel. With the 3D printing technology, consumers can get 3D furniture sample, from which you can see the effect of changes in furniture, select programs carefully and adjust timely.

3D Combined with VR Technology to Make Cross-border Furniture Industry Accessible. The technology of VR sets off a new wave in 2016, the 3D combined with VR technology will promote the rapid development of furniture scenarized sales in the future, to cope with the increase in business costs and labor costs. Affected by high business costs, more and more companies will try to use visual and scene technology, to satisfy consumers on demand of different styles with a richer vision. Interactive 3D dynamic visual and physical behavior allows consumers to immerse themselves in a real indoor environment, with all kinds of home styles and supporting household products, as to make consumers choose furniture as well as consider interior decoration and specific furniture products at the same time. In this way, consumers save their time and effort, the sross-border integration of the furniture industry slso promote.

\section{Summary}

In nowadays with rapid economic development, Our way of life has changed dramatically, it is more convenient for us to get information and more diversified purchase channels. The 3D effect of furniture design is a kind of quick and comprehensive performance, by its deep integration with electronic commerce, the furniture enterprises must be promoted to change trend, save resources, improve efficiency and reduce costs, in order to achieve efficient operation.

\section{References}

[1] Tao Tao, Furniture design and development (Chemical Industry Press, China 2012 )

[2] Gong Wenxiang, How to do the traditional electricity supplier and micro electricity supplier (Publishing House of electronics industry, China 2015)

[3] Zhu Jiang, Chinese version of 3DS Max 2014 technology Daquan(People's Posts and Telecommunications Press, China 2014)

[4] B.Y.Liu and G.Y.Di: Design Research,Vol.20(2016)No.6,p.116-121

[5] H.F.Wang,Q.Wu and P.F.Jiang: Furniture \& Interior Design,Vol.16(2016)No.11,p100-101

[6] F.Zhang, Y.Xu and S.H.Xu: Computer Era,Vol.07(2016)No.1,p.52-55

[7] W.Tian: Art Science and Technology, Vol.29 (2016) No.7, p.35

[8] W.J.Li: Arts Circle.Vol.13(2015)No.01:76-77

[9] X.Li,R.J.Li and X.P.Cui: Times Finance,Vol.11(2016)No.7,p.202.204

[10] R.B.Wang: Construcion Materials \& Decoration, Vol.22(2016)No.34,p.136 